Int. J. Morphol.,

34(1):223-231, 2016.

\title{
Mestizo Anterior Teeth's Proportions
}

\author{
Proporciones de los Dientes Anteriores en una Población Mestiza
}

Luis Miguel Ramirez; Juan David Ospina** \& Luis Ernesto Ballesteros ${ }^{* * * *}$

RAMIREZ, L. M.; OSPINA, J. D. \& BALLESTEROS, L. E. Mestizo anterior teeth's proportions. Int. J. Morphol., 34(1):223-231, 2016.

SUMMARY: Teeth proportions relate to beauty and harmony but aesthetic dental ideal proportion models show inconsistent results. Golden Proportion's, Preston's, Fayyad's, Snow's, and Ward's models where characterized for best fit in a Colombian mestizo population anterior teeth. Models of teeth's beauty proportions (Golden Proportion's, Preston's, Fayyad's, Snow's, and Ward') are analyzed for best fit in a mestizo (mixed race) Colombian population and variables as sex, aesthetic balance or history of previous orthodontic treatments were also analyzed for their probable impact on the distribution of the dental proportions. It was used standardized photographs of anterior teeth on 351 individuals of both sexes with complete erupted and healthy teeth. The measurements were done by calibrated computer software (error of $0.05 \mathrm{~mm}$ ). A Chi squared test was used to check whether sex, aesthetic balance and previous orthodontic treatment had an impact on the distribution of the dental proportions. Also a nonparametric Wilcoxon test was used to analysis the null hypothesis. A cluster analysis using $\mathrm{k}$ means was carried out to search for subgroups, which better explain the distribution of anterior dental proportions in the sample. For the considered results the null hypothesis of the mean equaling to the Golden Proportion was rejected (Wilcoxon test $\mathrm{p}$ value $<0.001$ ). For the whole population, the Chi squared test did not reject the null hypothesis of equal proportions among the groups with respect to the sex ( $\mathrm{p}$ value $=0.56)$, aesthetic balance $(p$ value $=0.98)$ and history of previous orthodontic treatments $(p$ value $=0.67)$ variables. For the aesthetically balanced individuals, the Chi squared test also failed to reject the null hypothesis of equal proportions among the groups with respect to the sex $(p$ value $=0.63)$ and history of previous orthodontic treatments $(p$ value $=0.93)$ variables. Two Gaussian distributions were found for RED models fitting well in $58 \%$ for RED $70 \%$ (0.7 SD 0.03) and $42 \%$ for RED 75 (0.75 SD 0.025). From the cluster analysis using k means, two groups were identified in the whole sample. No universal model can describe the whole population but is possible to find a set of models for the different population subgroups. Aesthetically ideals are open to interpretation. Clinical aesthetically standards for ideal teeth proportions are open to interpretation in a mestizo (mixed raced) population.

KEY WORDS: Tooth morphology; Teeth proportions; Anterior teeth; Proportions models; Mestizo population.

\section{INTRODUCTION}

For the dental professional, achieving teeth harmony could be difficult due to this goal being directly related to a suitable and symmetrical dental proportion. This topic is of human concern since Egyptians and posteriorly with Euclid and Plato 1.618:1 golden proportion (GP) or divine proportion (Greek letter phi $[\phi])$. Mathematically and geometrically this number relates the ideal balance betwee two different body parts and originally tried to explain beauty and harmony in the art and also nature growing patterns.

Nowadays, aesthetic dental variables like proportion, symmetry, harmony and dominance (dependent from teeth size, form and position), have been reexamined by several researchers that have proposed models in an attempt to explain a universal beauty for teeth proportions. Without considering the variation of this measure and accepting them as an absolute model is a probable straightforward bet (Parnia et al., 2010). Inconsistent results could be endorsed to the heterogeneous population trait factor with dissimilar phenotypes related to size and form of teeth and maxillary arcades. Mixed race populations like Colombian mestizo one ancestrally originates from an unbalanced mixture of Amerindian, Afro descendant and European people like others already measured (de Castro et al., 2006).

Lombardi was the first to relate the relative width of frontal teeth (regressive anteroposterior visual width). (Lombardi, 1973). With this in mind, the maxillary dental arches observed from an anterior position generates a

* Faculty of Dentistry Associate Professor, Universidad de Antioquia, Medellin, Colombia.

** Université de Rennes 1, Rennes, France.

**** Basic Science Department Titular Professor, Universidad Industrial de Santander, Bucarmanga, Colombia. 
stereoscopic visual effect of apparent dimensions that create an anteroposterior vestibular perspective of surface shrinking that accomplish a 1.618:1 in a regressive proportion. GP could fit mathematically but its application on teeth is difficult. Under greater scrutiny GP as an absolute measure is naïve when morphometric of any structure should consider variation (Ricketts, 1982; Forster et al., 2013; Murthy \& Ramani, 2008; Mahshid et al., 2004; Meshramkar et al., 2013; Umer et al., 2010; Huang et al., 2012; Condon et al., 2013; Becerra Santos et al., 2015; Gillen et al., 1994).

GP as a mathematical reason represent for a minor structure a $62 \%$ of a major one. Applying this to anterior teeth the lateral gauge central's $62 \%$ and so canine the lateral $62 \%$ (Sulaiman et al., 2010; Hasanreisoglu et al., 2005). Together, from central to canine the proportion must be 1.6:1:0.6 (Ricketts). This ratio has also failed in craniofacial measures like interpupilar, intercantal, interalar, intercigomatic to teeth's GP (Gomes et al., 2006; Mizumoto et al., 2009; Al-Marzok et al., 2013; Isa et al., 2010). Moreover, some surveys to computer modified anterior teeth photos have not clear agreement (Rosenstiel et al., 2000; Wolfart et al., 2006; Ker et al., 2008; Cooper et al., 2012).

Several researchers have explored ideal proportions' models that can be resumed as GP's, Preston's, Fayyad's, Snow's, and Ward's ones. Ward suggested a variety "Recurring Esthetic Dental" or RED as $70 \%, 75 \%, 80 \%$ different to $62 \%$ of the GP (Ricketts; Preston, 1993; Snow, 1999; Ali Fayyad et al., 2006; Ward, 2007). With the aim of characterizing and finding the models that best fit the proportions of anterior teeth in a Colombian mestizo population, they were estimated and compared. A cluster analysis was also performed on the dental proportions in this population to finally conclude that no universal model exist that can describe the whole population but that it is possible to find a set of models for the different population subgroups. The implications of this in the practice are discussed in the conclusions of this report.

\section{MATERIAL AND METHOD}

Population and dental measurements. Standardized photographs of anterior teeth were taken by one operator on 351 individuals of both sexes with complete erupted and healthy teeth. The Ethics Committee of the Universidad de Antioquia approved the research. Patient consent was obtained before taking the photographs. Photos were taken with lip retractor (PTJ Intl Co, Houdemont, France) in seated position and occipital support keeping the Frankfort plane parallel to the floor.
Exclusion criteria were: diastemas, congenital absence, malformation or supernumerary teeth, crown damage, prosthetic treatment (crowns, resins and veneers).

Photographic standardization: the operator used an IE3 Canon camera (12 megapixels) with $100 \mathrm{~mm}$ Canon macro and a Sigma ring flash. In the sagittal plane camera lens focus was centered with teeth middle line. Transversal paralleling plane was obtained matching the horizontal lens grid with the intercanine plane. Macro was used in manual mode and in proportion 1:2 that keeps invariable light, distance focus register and teeth comparison between volunteers. To obtain campus depth focus the higher diaphragm was used.

Teeth measurements were obtained (by one operator) with PhotoShop rule (Adobe Photoshop CS6; Adobe Systems Inc., San Jose, Calif.). PhotoShop rule was configured using a $10 \mathrm{~mm}$ Mitutoyo's caliper image in same proportion (2:1) of the teeth photos. Image measuring precision was confirmed using some volunteers' dental stone models as controls of the same measures with a centesimal error found of $0.05 \mathrm{~mm}$. Subsequently, six visual lengths of each anterior upper tooth (A13, A12, A11, A21, A22, A23) were taken by registering the widest incised middle zone of each teeth perpendicular to the major teeth axis (Fig. 1). Data were recorded on Excel (Excel; Microsoft Corp, Redmond, Wash.) and analyzed in R statistical software.

Dental proportion quantification. For all the participants the proportions A22/A21, A23/A22, A12/A11, A13/A12 were computed. A Chi squared test was used to test whether the following factors had an impact on the distribution of the dental proportions: sex, aesthetic balance and previous orthodontic treatment. We computed the fraction of proportions lying in the range 0.55 to 0.64 . A nonparametric Wilcoxon test was used to test the null hypothesis that proportions were distributed with mean 0.62 .

Fitting of different dental models. The following models were used to describe dental proportions in the sample: GP, Fayyad, Snow, Preston, Ward (RED $70 \%-75 \%-80 \%$ ), a general RED one. For the GP, Fayyad, Snow, Preston and $\operatorname{RED}(70 \%-75 \%-80 \%)$ it was proceeded as follows: for each individual the width of each tooth was predicted using all the models; for each tooth it was obtained the prediction error as the difference between the model prediction and the actual measure. For example, for the GP model, for each subject in the sample it was computed A12 as $0.62 * \mathrm{~A} 11$ and A13 as $0.62 * \mathrm{~A} 12$, and so on (Fig. 2). A standard t test was used to test the null hypothesis that the prediction error was distributed with zero mean. It was also plot the corresponding histograms for each model and each tooth (Figs. 3-6). 


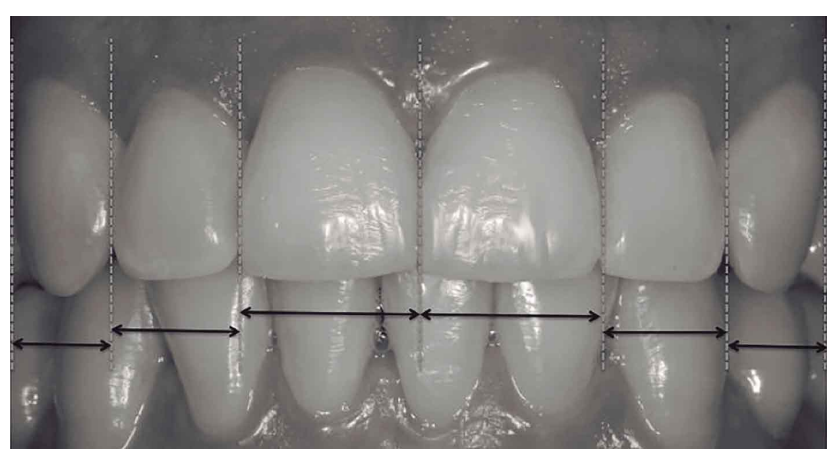

Fig. 1. Colombian mestizo's aesthetically balanced smile with proportions with pleasing symmetry and dominance.

General RED model. A general RED model was derived from the expression $\mathrm{ICd}=(\mathrm{A} 11+\mathrm{A} 21) \times(1+\mathrm{p}+\mathrm{p} 2)$, where ICd represents the intercanine distance and $\mathrm{p}$ is a proportion parameter. For RED-70, RED-75 and RED-80 models the proportion parameter $\mathrm{p}$ takes the values of 0.7 , 0.75 and 0.80 , respectively. This parameter $\mathrm{p}$ can be interpreted as the average dental proportion for a single individual. It was thus define the quantity $\ulcorner$ as:

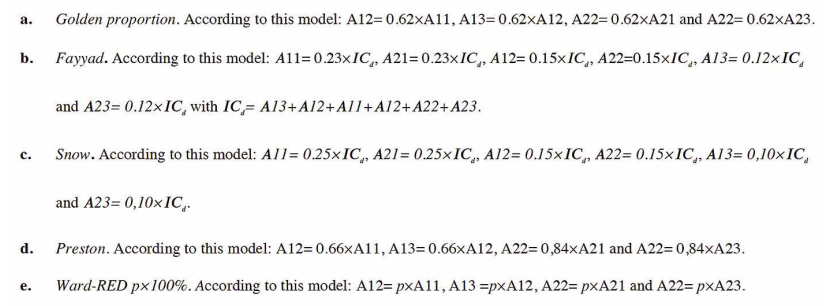

Fig. 2. Supplementary Data - Models of dental proportion S1.

$$
\Gamma=\mathrm{IC} \_\mathrm{d} /(\mathrm{A} 11+\mathrm{A} 21)=\left(1+\mathrm{p}+\mathrm{p}^{\wedge} 2\right)
$$

For each subject we computed $\mathrm{p}$ as the positive solution of the second order equation $0=1-\left\lceil+p+p^{\wedge} 2\right.$. The value of the average dental proportion parameter $\mathrm{p}$ was computed for each individual and it was tested whether or not the distribution of this parameter in the sample could be described by a Gaussian distribution or a mixture of
AA12

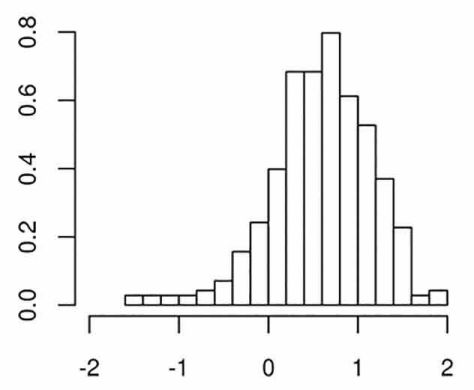

Actual-Model predicted [mm]

AA13

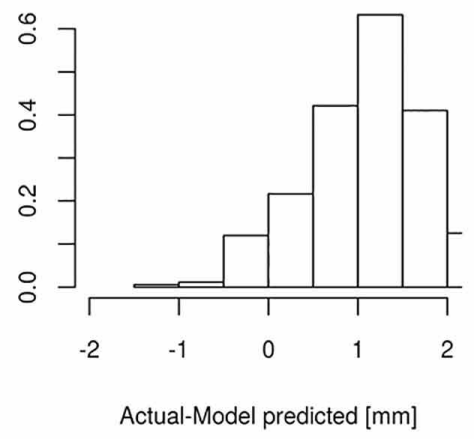

AA22

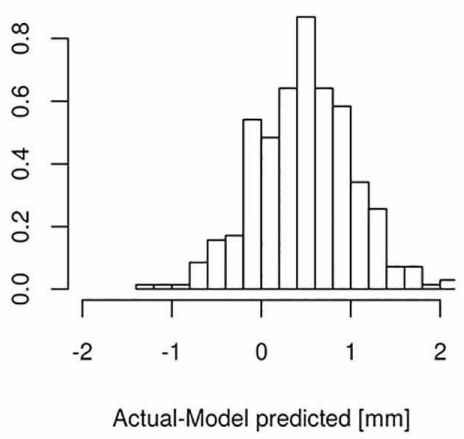

AA23

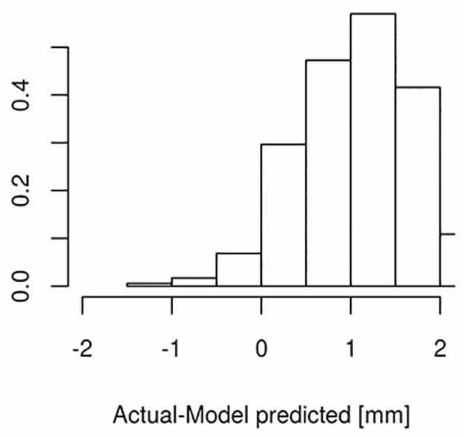

Fig. 3. Histograms of the prediction error for Golden Proportion model. 

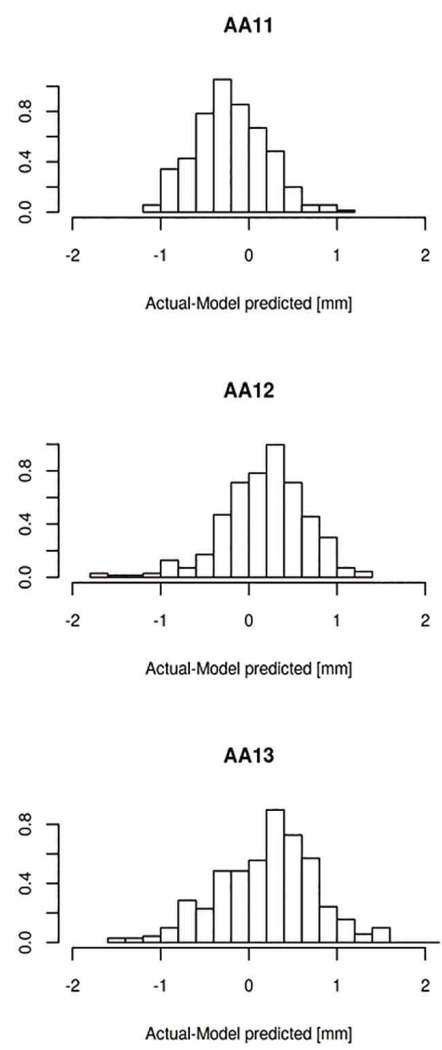

Fig. 4. Histograms of the prediction error for Fayyad model.
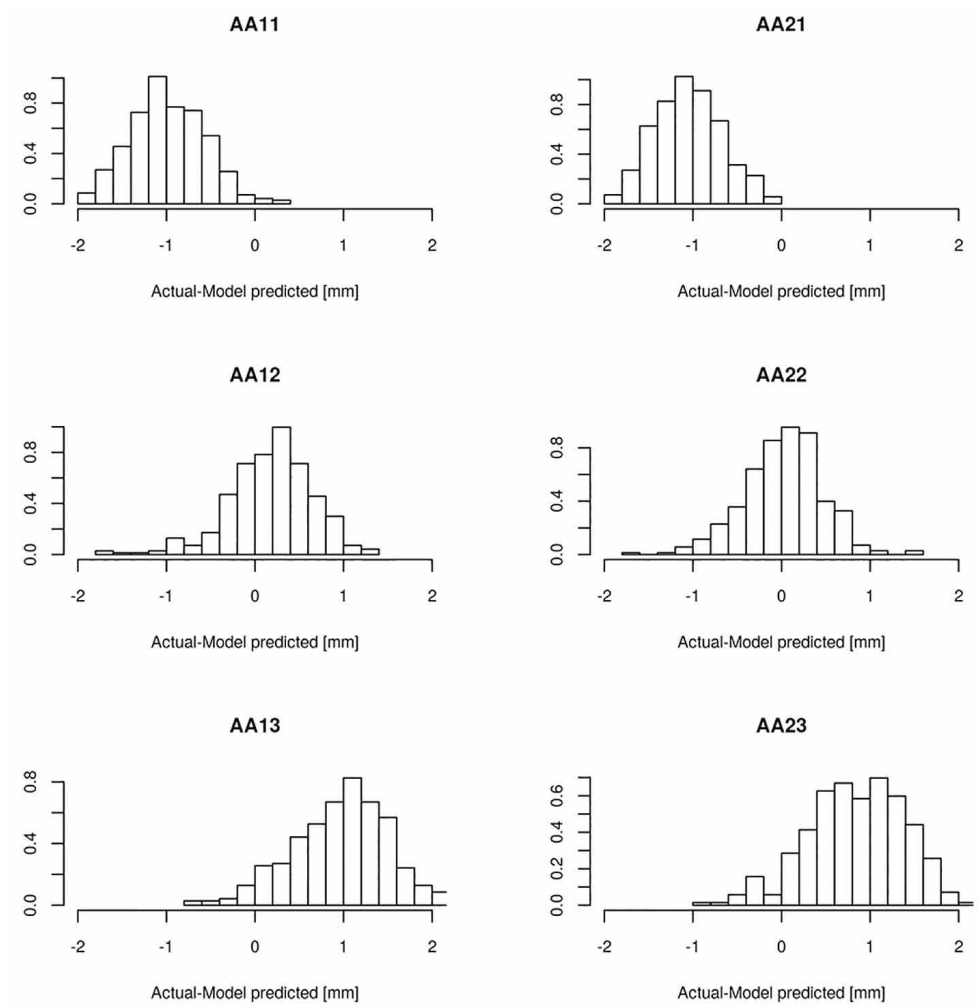

Fig. 5.Histograms of the prediction error for Snow model.
Gaussian distributions. This was carried out using the expectation maximization algorithm (EM) and the Aikake's information criterion (AIC) was used to define the number of Gaussians in the mixture.

Cluster analysis. A cluster analysis using $\mathrm{k}$ means was carried out to search for subgroups within the sample, which better explains the distribution of anterior dental proportions in the sample. In a first step, it was aimed at identifying sub groups in the whole sample and in a second step, we searched for groups within the aesthetically balanced subjects. Chi squared test was used to test whether some of the considered variables (sex, aesthetic balance or history of previous orthodontic treatments) had an effect on the formation of the groups. All the statistical analysis was performed using the $\mathrm{R}$ software.

\section{RESULTS}

Sample consisted in male (202) and female (149). Age range was $18-40(\mathrm{SD}=4.59)$. About $38 \%$ of the individuals had a history of previous orthodontic treatments, and $34 \%$ of the individuals were classified by the same expert as aesthetically balanced. Among the individuals with a history of previous orthodontic treatments, $46 \%$ were classed as aesthetically balanced whereas only $26 \%$ of the individuals without history of previous orthodontic treatments were classed as aesthetically balanced (Chi squared test $\mathrm{p}$ value $<0.001)$.

The descriptive statistics for the anterior dental proportions are presented (Table I). It also presents the $p$ values of the Wilcoxon test testing the null hypothesis that there is no difference (in the mean) among groups defined by the corresponding variable (sex, aesthetic balance and history of orthodontic treatment) and it also shows the percentage of anterior dental proportions lying within the range $0.55-0.64$.

For the considered proportions the null hypothesis of the mean equaling to the GP was rejected (Wilcoxon test $\mathrm{p}$ value $<0.001$ ). Errors and standard deviations of the predictions of the different models are related (Table II). 
AA12

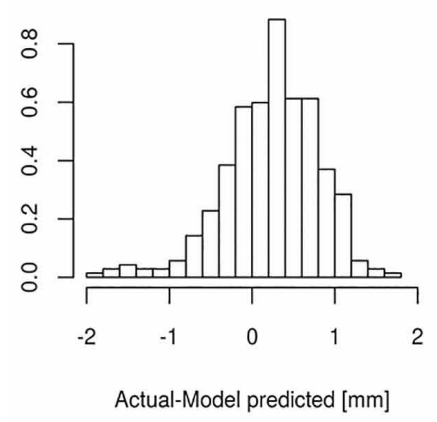

AA13

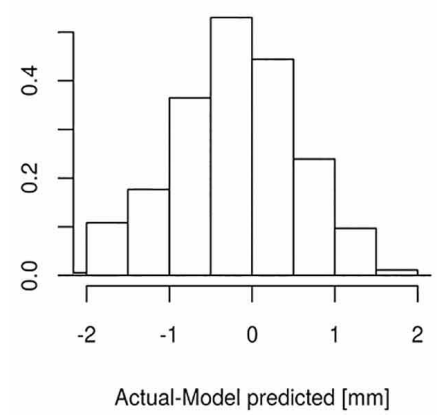

AA22

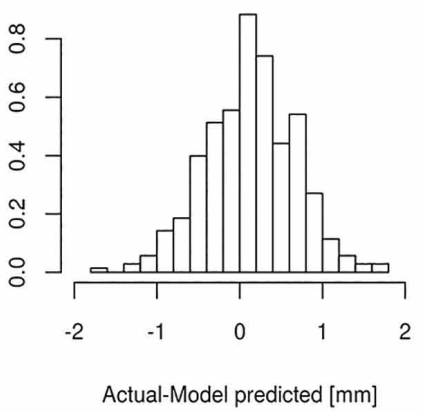

AA23

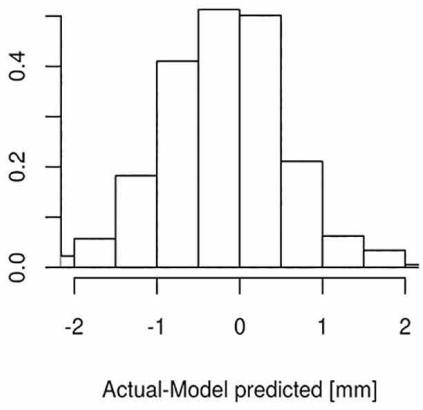

Fig. 6. Histograms of the prediction error for Preston model.

Table I. Descriptive statistics of the population anterior dental proportions. *: p value of the Wilcoxon test of the null hypothesis that there is no difference among groups defined by the corresponding variable; Aesth. Bal.: aesthetic balance; Hist. Orth.: history of previous orthodontic treatments.

\begin{tabular}{lcccc}
\hline & A22/A21 & $\mathbf{A 2 3} / \mathbf{A 2 2}$ & $\mathbf{A 1 2} / \mathbf{A 1 1}$ & $\mathbf{A 1 3 / A 1 2}$ \\
\hline Min. & 0.47 & 0.45 & 0.45 & 0.47 \\
Median & 0.68 & 0.82 & 0.69 & 0.81 \\
Mean & 0.68 & 0.82 & 0.69 & 0.82 \\
Max. & 0.72 & 0.89 & 0.73 & 1.63 \\
SD & 0.06 & 0.13 & 0.06 & 0.14 \\
Sex (p value)* & 0.41 & 0.29 & 0.07 & 0.75 \\
Aesth. Bal. (p value)* & 0.87 & 0.48 & 0.20 & 0.22 \\
Hist. Orth. (p value)* & 0.06 & 0.95 & 0.00 & 0.56 \\
\% (0.55-0.64) & 25.64 & 5.41 & 17.66 & 6.8 \\
\hline
\end{tabular}

A mixture of two Gaussian distributions for the parameter $\mathrm{p}$ of the general Ward-RED model was fit to our sample. Figure 7 presents the histogram of the parameter $\mathrm{p}$ as well as the nonparametric fit of this histogram and the two Gaussian densities of the mixture. The parameters of the mixture were mean $=0.7$ and $\mathrm{SD}=0.03$, for the first Gaussian (which represents $58 \%$ of population) and mean $=0.75$ and $\mathrm{SD}=0.025$ for the second Gaussian (which represents $42 \%$ of population). The mean and standard deviation for the error predictions for this model are also shown (Table II, Mixture of WR).

From the cluster analysis using k means, two groups were identified in the whole sample. The centers of both groups and the standard deviation of each anterior dental proportion are presented (Table III). Regarding the aesthetically balanced individuals, two groups were also identified (Table IV). For the whole population, the Chi squared test did not reject the null hypothesis of equal proportions among the groups with respect to the sex ( $p$ value $=0.56$ ), aesthetic balance ( $\mathrm{p}$ value $=0.98)$ and history of previous orthodontic treatments ( $p$ value $=0.67$ ) variables. For the aesthetically balanced individuals, the Chi squared test also failed to reject the null hypothesis of equal proportions among the groups with respect to the sex ( $p$ value $=0.63)$ and history of previous orthodontic treatments $(p$ value $=0.93)$ variables. Figures 8 and 9 present the scatter plots of the dental proportions and illustrate the distribution of the groups in the whole sample and in the aesthetically balanced individual.

Table II. Mean errors and standard deviations (both in $\mathrm{mm}$ ) for the predicted measurements of the different models. *: the p value of the Wilcoxon test testing if the errors have mean equal to zero was $<0.01$; WR: Ward-Red.

\begin{tabular}{lcccccc}
\hline Model & A13 & A12 & A11 & A21 & A22 & A23 \\
\hline GP & $1.14^{*}(0.73)$ & $0.59^{*}(0.56)$ & --- & --- & $0.48^{*}(0.54)$ & $1.11^{*}(0.68)$ \\
Fayyad & $0.21^{*}(0.57)$ & $0.18^{*}(0.48)$ & $-0.21^{*}(0.40)$ & $-0.27 *(0.36)$ & $0.02(0.45)$ & $0.07 *(.055)$ \\
Snow & $0.98^{*}(0.57)$ & $0.18^{*}(0.48)$ & $-0.98^{*}(0.41)$ & $-1.05^{*}(0.38)$ & $0.02(0.45)$ & $0.85^{*}(0.55)$ \\
Preston & $-0.18^{*}(0.82)$ & $0.24^{*}(0.58)$ & --- & --- & $0.13 *(0.54)$ & $-0.18^{*}(0.75)$ \\
WR-70 \% & $0.67 *(0.76)$ & $-0.11^{*}(0.57)$ & --- & --- & $-0.22^{*}(0.55)$ & $0.64 *(0.71)$ \\
WR-75 \% & $0.36^{*}(0.78)$ & $-0.54 *(0.58)$ & --- & --- & $-0.65^{*}(0.55)$ & $0.35^{*}(0.72)$ \\
WR-80 \% & $0.06(0.80)$ & $-0.99^{*}(0.59)$ & --- & --- & $-1.08^{*}(0.56)$ & $0.06(0.74)$ \\
Mixture of WR & $0.54 *(0.75)$ & $-0.28^{*}(0.51)$ & --- & --- & $-0.38^{*}(0.47)$ & $0.52 *(0.70)$ \\
\hline
\end{tabular}


RAMIREZ, L. M.; OSPINA, J. D. \& BALLESTEROS, L. E. Mestizo anterior teeth's proportions. Int. J. Morphol., 34(1):223-231, 2016.

Table III. Results of the clustering analysis in whole sample. XX (YY): Center the cluster (group standard deviation).

\begin{tabular}{lcccc}
\hline & A22/A21 & A23/A22 & A12/A11 & A13/A12 \\
\hline Group 1 (59\%) & $0.70(0.06)$ & $0.74(0.09)$ & $0.71(0.05)$ & $0.74(0.09)$ \\
Group 2(41\%) & $0.64(0.06)$ & $0.92(0.11)$ & $0.65(0.06)$ & $0.94(0.13)$ \\
\hline
\end{tabular}

Table IV. Results of the clustering analysis in the subset of aesthetically balanced subjects. $\mathrm{XX}$ (YY): Center the cluster (group standard deviation).

\begin{tabular}{lcccc}
\hline & A22/A21 & A23/A22 & A12/A11 & A 13/A12 \\
\hline Group 1 (58 \%) & $0.69(0.05)$ & $0.74(0.07)$ & $0.70(0.05)$ & $0.76(0.08)$ \\
Group 2 (42\%) & $0.65(0.05)$ & $0.90(0.08)$ & $0.66(0.06)$ & $0.93(0.09)$
\end{tabular}

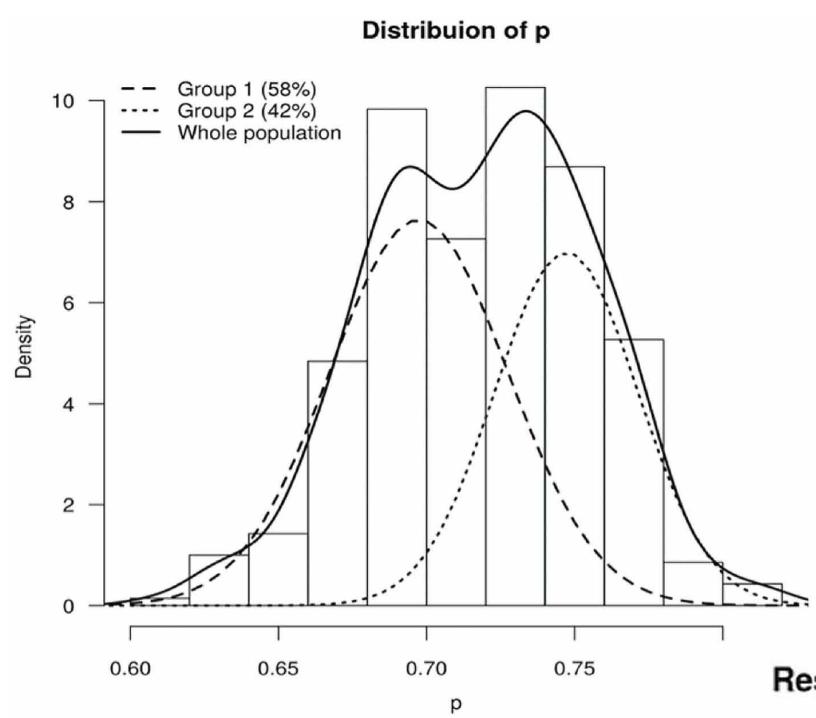

Fig. 7. Histogram of the distribution of the p parameter estimation. The dash line is a nonparametric fit of the whole population. The red line is a Gaussian density (mean $=0.7$ and $\mathrm{SD}=0.03$ ), which describes $58 \%$ of the sample, and the green line is a Gaussian density (mean $=0.75$ and $\mathrm{SD}=0.025$ ), which represents the 42 $\%$ of the sample.

Fig. 8. Scatter plot of the groups for the whole sample.
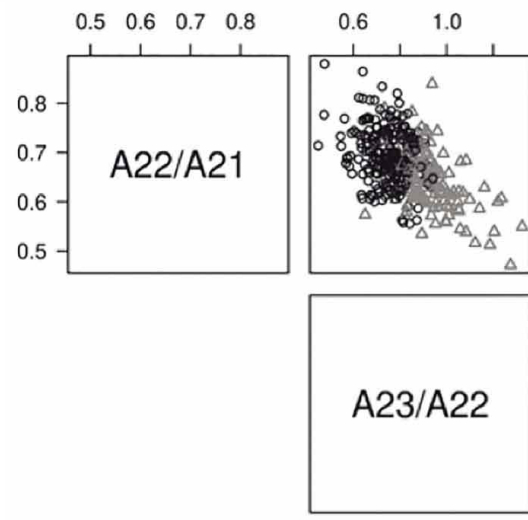

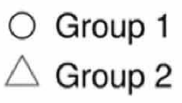 \\ Group 2}

Group 1 center:

A22/A21 $=0,70 ;$ A23/A22 $=0,74 ; \mathrm{A} 12 / \mathrm{A} 11=0,71 ; \mathrm{A} 13 / \mathrm{A} 12=0,74$ Group 2 center:

A22/A21 $=0,64 ; \mathrm{A} 23 / \mathrm{A} 22=0,92 ; \mathrm{A} 12 / \mathrm{A} 11=0,65 ; \mathrm{A} 13 / \mathrm{A} 12=0,94$
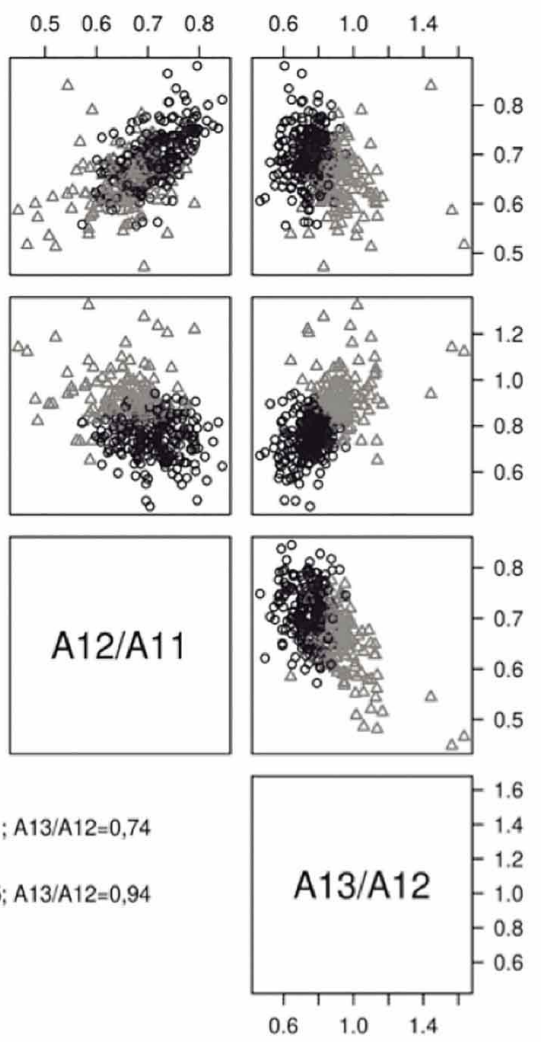
Fig. 9. Scatter plot of the groups for the aesthetically balanced individuals.

Results from the cluster analysis (aesth. bal.)
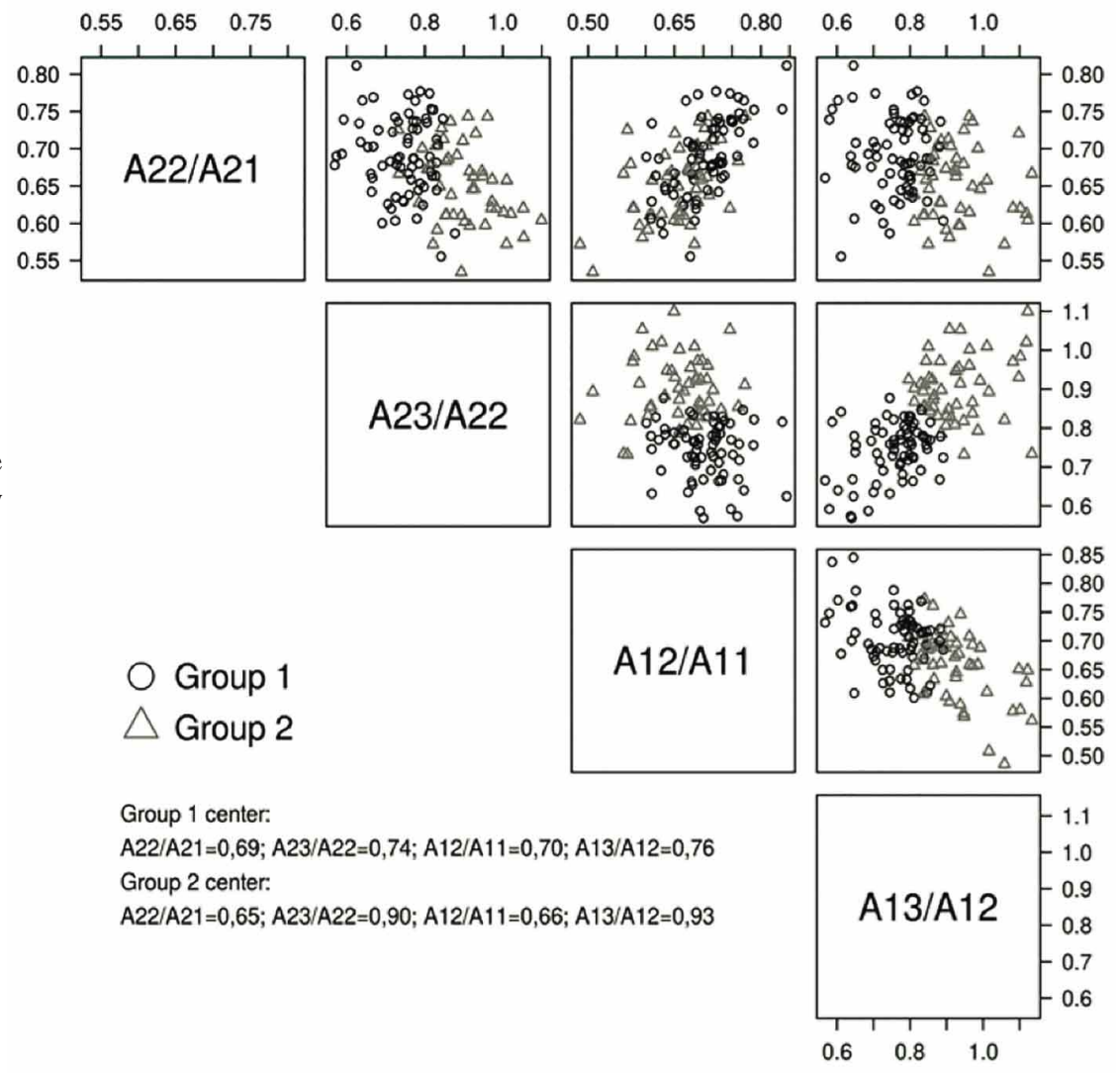

\section{DISCUSION}

Five proposed models were fit with ideal dental proportions to a Mestizo Colombian sample with best fit in Preston model (Fig. 6) for lateral/central and canine/lateral proportion with 0.68 and 0.82 respectively compared with Preston models 0.66 and 0.84 . Similarly, RED models showed some population fitting well in RED $70 \%$ and $75 \%$ in two groups of our sample: $58 \%$ adjusting for RED 70 (0.7 SD 0.03 ) and $42 \%$ adjusting for RED 75 (0.75 SD 0.025), shown in Figure 7. These heterogonous results that fit, in an spared form, for two models is not surprising due to close range between all purposed models, also for the mixed raced population found in Colombia. In Figures 3-6 shows the worst models for this sample (GP's, Fayyad's and Snow's ones).

In several populations researchers have shown contrasting results. Preston found a proportion $0.62-0.66$ (central-lateral) and 0.84 (lateral-canine) and narrower teeth if applying GP. He demonstrated that only $17 \%$ of GP were observed in central-lateral correlation. Equally, Sulaiman $e t$ $a l$. found near values correspondingly $(0.7$ and 0.82$)$ different to 0.62 in Malay. Ward suggested RED $70 \%, 75 \%$ and 80 $\%$ proportions with a central to canine percentage distribution of 25-15-10\%. Ali Fayyad et al. in a Jordan population found a distinctive one (23-15-12\%), with a proportion 1.53:1:0.8 been agreed with Hasanreisoglu et al. Other example of this variability is presented by Foster $\mathrm{et} \mathrm{al}$., with Hungarian population with 1.6:1:0.85. Murthy \& Ramani, Mashid et al., Meshramkar et al., Becerra Santos et al., and Guillen $e t$ al. failed to find a solid relationship between GP and size of anterior in teeth in Indian, Iranians, Colombians and North Americans. With this in mind, there appears to be a clear need of proportion adjustment in each ethnic group.

No association was found between the proportions and variables related to best or ideal aesthetic balance, previous orthodontic treatments, side or sex. Side variable in this paired sample suggest a good symmetry balance between left and right proportions. Related to sex the probable sexual dimorphism factor influencing discrepancies in sex were not found in this research agreeing with Sulaiman et al., Umer et al., and others (Huang et al.). Sex dimorphism must be understood in a morphometric measurement but not in a proportion feature that discloses that in an aesthetic point of view teeth size do not influence beauty. 
Almost one third of the whole population (34\%) was classified as aesthetically balanced. Orthodontic therapies were registered in the $38 \%$ of the whole sample and within this almost half (46\%) accomplish aesthetic balance in contrast to $26 \%$ with aesthetic balance found in individuals without history of previous orthodontic therapy (Chi squared test $\mathrm{p}$ value $<0.001)$. In the same direction the results cannot found association between volunteers with previous orthodontic treatment and ideal proportions. Apparently, the above suggests a controversial orthodontic treatment goal against therapy for the attainment of aesthetic balance impact. However, orthodontic treatment is considered a dichotomy variable with questionable reliability due to the loss of detailed information about therapy length, quality, difficulty grade and maintenance.

In relation to ideal proportions we agree with Murthy \& Ramani, that this concept can be applied if proportions are adjusted, considering the ethnicity of the population and ideal models of proportions are not advisable for a general application. Mashid et al. suggest a cultural perception of beauty for teeth balance due to ideal beauty is not an absolute pattern. With this in mind and according to Condon et al., GP guidelines could only be applied to the lateral/central proportion (0.618) and proposed other proportions ( 0.58 and 0.89 ) for the canine/central and canine/lateral proportions respectively.

Dental harmony doesn't work alone and demands a whole heterogeneous composition involving cranium (size and form), cranio-maxilo-mandibular proportions (maxillary transversal dimension), lips (size, form, smile line), healthy gums and finally teeth (size, form, proportion, middle line), considering age which all create harmony, balance and beauty. These on the other hand, can also be associated with unpleasant visual tension and ugliness.

\section{CONCLUSION}

1. Preston model best fit Colombian mestizo sample.

2. RED model $70 \%$ and $75 \%$ are adjusted in $58 \%$ and 42 $\%$ of the sample respectively.

3. Aesthetically ideals are open to interpretation.

\section{ACKNOWLEDGMENTS}

Digital pictures have been recorded from an approved project on Faculty of Dentistry Research Center. No conflict of interest declared.
RAMIREZ, L. M.; OSPINA, J. D. \& BALLESTEROS, L. E. Proporciones de los dientes anteriores en una población mestiza. Int. J. Morphol., 34(1):223-231, 2016.

RESUMEN: Las proporciones de los dientes se refieren a su belleza y armonía, pero los modelos de proporciones dentales estéticas ideales muestran resultados inconsistentes. La proporción Aurea y los modelos de Preston, Fayyad, Snow, y Ward fueron ajustados para caracterizar los dientes de una población colombiana mestiza. Modelos de proporciones de belleza de dientes (Proporción Aurea, Modelos de Preston, Fayyad, Snow y Ward) se analizaron para lograr alcanzar el mejor ajuste en una población colombiana mestiza (mezcla de razas), y también se analizaron las variables de sexo, equilibrio estético e historia de tratamientos de ortodoncia previos para evaluar su probable impacto sobre la distribución de las proporciones dentales consideradas. Fueron utilizadas fotografías estandarizadas de dientes anteriores de 351 individuos de ambos sexos con dientes completamente erupcionados y sanos. Las mediciones fueron realizadas con programas informáticos calibrados (error de 0,05 mm). Se utilizó la prueba Chi Cuadrado para comprobar si el sexo, el equilibrio estético y el tratamiento ortodóncico previo tuvieron un impacto en la distribución de las proporciones dentales. También se utilizó la prueba no paramétrica de Wilcoxon para el análisis de la hipótesis nula. Un análisis de conglomerados, utilizando la media k, se llevó a cabo para buscar subgrupos, que explicaron mejor la distribución de proporciones dentales anteriores en la muestra. Para que los resultados fueran considerados, la hipótesis nula de la media que equivale a la proporción áurea fue rechazada (Prueba de Wilcoxon, valor $\mathrm{p}<0,001)$. Para toda la población, la prueba de Chi Cuadrado no rechazó la hipótesis nula de proporciones iguales entre los grupos con respecto al sexo (valor de $\mathrm{p}=$ 0,56 ), equilibrio estético (valor de $\mathrm{p}=0,98$ ) y la historia de tratamientos de ortodoncia previos ( valor de $\mathrm{p}=0,67$ ). Para los individuos estéticamente balanceados, la prueba de Chi Cuadrado tampocó rechazó la hipótesis nula de proporciones iguales entre los grupos con respecto a las variables de sexo (valor $\mathrm{p}=0,63$ ) y la historia de los tratamientos de ortodoncia anteriores (valor $\mathrm{p}=0,93$ ). Se encontraron dos distribuciones gaussianas para los modelos RED que encajaron bien en el $58 \%$ para RED $70 \%(0,7$ DE 0,03$)$ y el $42 \%$ para RED 75 $(0,75$ DE 0,025$)$. Con respecto al análisis de los conglomerados a través de las medias k, se identificaron dos grupos en toda la muestra. No hay un modelo universal que pueda describir toda la población, pero es posible encontrar un conjunto de modelos para los diferentes subgrupos de población. Los ideales estéticamente están abiertos a interpretación. Las normas clínicas de estética para dientes con proporciones ideales están abiertos a interpretación en una población mestiza.

PAlabras ClaVE: Morfología dentaria; Proporciones dentarias; Dientes anteriores; Modelos de proporciones; Población mestiza. 


\section{REFERENCES}

Al-Marzok, M. I.; Majeed, K. R. \& Ibrahim, I. K. Evaluation of maxillary anterior teeth and their relation to the golden proportion in Malaysian population. BMC Oral Health, 13:9, 2013.

Ali Fayyad, M.; Jamani, K. D. \& Agrabawi, J. Geometric and mathematical proportions and their relations to maxillary anterior teeth. J. Contemp. Dent. Pract ., 7(5):62-70, 2006.

Becerra Santos, G.; Becerra Moreno, N.; Jiménez Arango, M.; Medina Piedrahita, V. M.; Tamayo López, L. C. \& Gómez, S. L. Algunos factores relacionados con la estética dental: una nueva aproximación. Rev. Fac. Odontol. Univ. Antioq., 26(2):271-91, 2015.

Condon, M.; Bready, M.; Quinn, F.; O'Connell, B. C.; Houston, F. J. \& O'Sullivan, M. Maxillary anterior tooth dimensions and proportions in an Irish young adult population. J. Oral Rehabil., 38(7):501-8, 2011.

Cooper, G. E.; Tredwin, C. J.; Cooper, N. T.; Petrie, A. \& Gill, D. S. The influence of maxillary central incisor height-to-width ratio on perceived smile aesthetics. Br. Dent. J., 212(12):589-99, 2012.

de Castro, M. V.; Santos, N. C. \& Ricardo, L. H. Assessment of the "golden proportion" in agreeable smiles. Quintessence Int., 37(8):597-604, 2006.

Forster, A.; Velez, R.; Antal, M. \& Nagy, K. Width ratios in the anterior maxillary region in a Hungarian population: addition to the golden proportion debate. J. Prosthet. Dent., 110(3):211-5, 2013.

Gillen, R. J.; Schwartz, R. S.; Hilton, T. J. \& Evans, D. B. An analysis of selected normative tooth proportions. Int. J. Prosthodont., 7(5):410-7, 1994.

Gomes, V. L.; Gonçalves, L. C.; do Prado, C. J.; Junior, I. L. \& de Lima Lucas, B. Correlation between facial measurements and the mesiodistal width of the maxillary anterior teeth. J. Esthet. Restor. Dent., 18(4):196205,2006

Hasanreisoglu, U.; Berksun, S.; Aras, K. \& Arslan, I. An analysis of maxillary anterior teeth: facial and dental proportions. J. Prosthet. Dent., 94(6):530-8, 2005.

Huang, S. Y.; Kang, T.; Liu, D. Y.; Duan, Y. Z. \& Shao, J. L. Variability in permanent tooth size of three ancient populations in Xi'an, northern China. Arch. Oral Biol., 57(11):1467-73, 2012.

Isa, Z. M.; Tawfiq, O. F.; Noor, N. M.; Shamsudheen, M. I. \& Rijal, O. M. Regression methods to investigate the relationship between facial measurements and widths of the maxillary anterior teeth. J. Prosthet. Dent., 103(3):182-8, 2010.

Ker, A. J.; Chan, R; Fields, H. W.; Beck, M. \& Rosenstiel, S. Esthetics and smile characteristics from the layperson's perspective: a computer-based survey study. J. Am. Dent. Assoc., 139(10):1318-27, 2008.

Lombardi, R. E. The principles of visual perception and their clinical application to denture esthetics. J. Prosthet. Dent., 29(4):358-82, 1973.

Mahshid, M.; Khoshvaghti, A.; Varshosaz, M. \& Vallaei, N. Evaluation of "golden proportion" in individuals with an esthetic smile. J. Esthet. Restor. Dent., 16(3):185-92, 2004.
Meshramkar, R.; Patankar, A.; Lekha, K. \& Nadiger, R. A study to evaluate the prevalence of golden proportion and RED proportion in aesthetically pleasing smiles. Eur. J. Prosthodont. Restor. Dent., 21(1):29-33, 2013.

Mizumoto, Y.; Deguchi, T. Sr. \& Fong, K. W. Assessment of facial golden proportions among young Japanese women. Am. J. Orthod. Dentofacial Orthop., 136(2):168-74, 2009.

Murthy, B. V. \& Ramani, N. Evaluation of natural smile: Golden proportion, RED or Golden percentage. J. Conserv. Dent., 11(1):16-21, 2008.

Parnia, F.; Hafezeqoran, A.; Mahboub, F.; Moslehifard, E.; Koodaryan, R.; Moteyagheni, R. \& Saleh Saber, F. Proportions of maxillary anterior teeth relative to each other and to golden standard in tabriz dental faculty students. J. Dent. Res. Dent. Clin. Dent. Prospects, 4(3):83-6, 2010.

Preston, J. D. The golden proportion revisited. J. Esthet. Dent., 5(6):247$51,1993$.

Ricketts, R. M. The biologic significance of the divine proportion and Fibonacci series. Am. J. Orthod., 81(5):351-70, 1982.

Rosenstiel, S. F.; Ward, D. H. \& Rashid, R. G. Dentists' preferences of anterior tooth proportion--a web-based study. J. Prosthodont., 9(3):123$36,2000$.

Snow, S. R. Esthetic smile analysis of maxillary anterior tooth width: the golden percentage. J. Esthet. Dent., 11(4):177-84, 1999.

Sulaiman, E.; Yaakub, M. S.; Zulkifli, N. A.; Abdullah, M. \& Gonzalez, M. A. G. Existence of golden proportion in maxillary anterior teeth of University of Malaya dental students. Ann. Dent. Univ. Malaya, 17(1):9$14,2010$.

Umer, F.; Khan, F. R. \& Khan, A. Golden proportion in visual dental smile in Pakistani population: A pilot study. Acta Stomatol. Croat., 44(3):168$75,2010$.

Ward, D. H. A study of dentists' preferred maxillary anterior tooth width proportions: comparing the recurring esthetic dental proportion to other mathematical and naturally occurring proportions. J. Esthet. Restor. Dent., 19(6):324-37, 2007.

Wolfart, S.; Quaas, A. C.; Freitag, S.; Kropp, P.; Gerber, W. D. \& Kern, M. Subjective and objective perception of upper incisors. J. Oral Rehabil., 33(7):489-95, 2006.

\section{Correspondence to: \\ Prof. LM Ramirez}

Laboratorio QST (225)

Facultad de Odontología

Calle 64 \# 52-59

Universidad de Antioquia

Medellin

COLOMBIA

\section{Email: Imra368@gmail.com}

Received: 10-08-2015

Accepted: 28-12-2015 